\title{
Cobalamin deficiency results in an abnormal increase in L-methylmalonyl- co-enzyme-A mutase expression in rat liver and COS-7 cells
}

\author{
Motoyuki Nakao ${ }^{1}$, Shoko Hironaka ${ }^{1}$, Naoki Harada ${ }^{1}$, Tetsuya Adachi ${ }^{2}$, Tomohiro Bito ${ }^{3}$, Yukinori Yabuta ${ }^{3}$, \\ Fumio Watanabe ${ }^{3}$, Takumi Miura ${ }^{1}$, Ryoichi Yamaji ${ }^{1}$, Hiroshi Inui ${ }^{1 *}$ and Yoshihisa Nakano ${ }^{1}$ \\ ${ }^{1}$ Department of Applied Biological Chemistry, Osaka Prefecture University, Sakai, Osaka 599-8531, Japan \\ ${ }^{2}$ International Center for Medical Research and Treatment, Kobe University School of Medicine, Kobe, Hyogo 650-0017, Japan \\ ${ }^{3}$ Faculty of Agriculture, Tottori University, Tottori, Tottori 680-8533, Japan
}

(Received 22 January 2008 - Revised 2 June 2008 - Accepted 3 June 2008 - First published online 19 August 2008)

The aim of the present study was to examine the effects of cobalamin (Cbl) on the activity and expression of L-methylmalonyl-CoA mutase $(\mathrm{MCM})$ in rat liver and cultured COS-7 cells. The MCM holoenzyme activity was less than $5 \%$ of the total (holoenzyme + apoenzyme) activity in the liver although rats were fed a diet containing sufficient Cbl. When weanling rats were maintained on a Cbl-deficient diet, the holo-MCM activity became almost undetectable at the age of 10 weeks. In contrast, a marked increase in the total-MCM activity occurred under the Cbldeficient conditions, and at the age of 20 weeks it was about 3-fold higher in the deficient rats than in the controls (108 (SD 14.5) v. 35 $(\mathrm{SD} 8.5) \mathrm{nmol} / \mathrm{mg}$ protein per $\min (n 5) ; P<0.05)$. Western blot analysis confirmed that the MCM protein level increased significantly in the Cbl-deficient rats. However, the MCM mRNA level, determined by real-time PCR, was rather decreased. When COS-7 cells were cultured in a medium in which $10 \%$ fetal bovine serum was the sole source of $\mathrm{Cbl}$, holo-MCM activity was barely detected. The supplementation of Cbl resulted in a large increase in the holo-MCM activity in the cells, but the activity did not exceed $30 \%$ of the total-MCM activity even in the presence of $\mathrm{Cbl}$ at $10 \mu \mathrm{mol} / \mathrm{l}$. In contrast, the total-MCM activity was significantly decreased by the $\mathrm{Cbl}$ supplementation, indicating that $\mathrm{Cbl}$ deficiency results in an increase in the MCM protein level in COS-7 cells as well as in rat liver.

Cobalamin deficiency: Methylmalonyl-CoA mutase: Holoenzymes: Methylmalonic acid: Rat liver: COS-7 cells

Cobalamin (Cbl; vitamin $\mathrm{B}_{12}$ ), when taken up into mammalian cells, is converted to its coenzyme forms, methylcobalamin and $5^{\prime}$-deoxyadenosylcobalamin $(\mathrm{AdoCbl})^{(1)}$. Mammals have two Cbl-dependent enzymes: methionine synthase (MS), for which methylcobalamin acts as a coenzyme, and L-methylmalonyl-CoA mutase (MCM), which requires AdoCbl as a prosthetic group ${ }^{(2)}$. MS catalyses the synthesis of methionine from homocysteine with 5-methyltetrahydrofolate as a methyl donor, and plays important roles in one-carbon and folate metabolism $^{(3)}$. In contrast, MCM localises in the matrix of mitochondria and catalyses the conversion of L-methylmalonyl-CoA (MMA-CoA) to succinyl-CoA, which is involved in the degradation pathways of certain amino acids (such as valine and isoleucine), odd-numbered fatty acids, cholesterol and thymine ${ }^{(1)}$.

Under Cbl-deficient conditions, MMA-CoA and its precursor, propionyl-CoA, increase in mammalian cells as a result of a decrease in the catalytic activity of MCM due to deficiency of $\mathrm{AdoCbl}^{(4)}$. Methylmalonic acid (MMA), which is produced by the hydrolysis of MMA-CoA, accumulates in the plasma and tissues, and is excreted abnormally into the urine (methylmalonic aciduria) ${ }^{(5,6)}$. The level of MMA in the urine is used as an index of Cbl deficiency ${ }^{(6,7)}$. The accumulations of MMA-CoA, propionyl-CoA and MMA lead to the disruption of normal metabolism in mammalian cells $^{(5)}$. In particular, MMA inhibits succinate dehydrogenase, which can lead to a decrease in respiratory activity ${ }^{(8)}$. The decrease of respiratory activity due to the accumulation of MMA is thought to be one of factors that cause severe growth retardation in mammals under Cbl-deficient conditions $^{(5)}$. In addition to $\mathrm{Cbl}$ deficiency, methylmalonic aciduria occurs in patients with some inherited diseases that occur due to the mutation of MCM or other genes involved in the pathway of AdoCbl synthesis ${ }^{(9,10)}$. In particular, inherited defects of the MCM gene are life-threatening for mammals, for example, MCM knock-out mice show neonatal lethality, although fetal development of the mice is normal ${ }^{(11)}$.

MCM becomes catalytically inactive under Cbl-deficient conditions due to the lack of its prosthetic group ${ }^{(1)}$; however, it is unclear whether the expression level of MCM is modulated in mammalian cells in response to a change in the level of $\mathrm{Cbl}$. In the present study, we report that the MCM protein level is abnormally increased in rat liver under Cbl-deficient conditions, even though the MCM mRNA level is rather

Abbreviations: AdoCbl, 5'-deoxyadenosylcobalamin; Cbl, cobalamin; MCM, L-methylmalonyl-CoA mutase; MMA, methylmalonic acid; MMA-CoA, methylmalonyl-CoA; MS, methionine synthase; OHCbl, hydroxocobalamin.

*Corresponding author: Dr Hiroshi Inui, fax +81 72254 9937, email inui@biochem.osakafu-u.ac.jp 
decreased. It is also reported that $\mathrm{Cbl}$ deficiency results in an increase in the MCM protein level in cultured COS-7 cells as well as rat liver.

\section{Materials and methods \\ Animals, diets and treatments}

Male weanling rats (age 3 weeks), born to 14-week-old parent rats, which had been fed a defatted soyabean-based Cbl-deficient diet, were used. The parent rats were obtained from Kiwa Laboratory Animals (Wakayama, Japan). The Cbl-deficient diet contained the following (per $\mathrm{kg} \mathrm{diet):}$ $400 \mathrm{~g}$ defatted soyabean (of which about $50 \%$ was crude protein and remainder carbohydrate; obtained from Showa Sangyo, Tokyo, Japan), $453 \mathrm{~g}$ glucose, $100 \mathrm{~g}$ soyabean oil, $35 \mathrm{~g}$ mineral mixture (AIN-93G-MX; Clea, Tokyo, Japan), $10 \mathrm{~g}$ Cbl-free vitamin mixture (AIN-93VX without Cbl; Clea) and $2 \mathrm{~g}$ choline chloride ${ }^{(12)}$. The weanling rats were randomly allocated to the Cbl-deficient and control (Cbl-sufficient) groups, and individually housed in wire-bottomed cages under controlled temperature $\left(22 \pm 2^{\circ} \mathrm{C}\right)$, humidity $(55 \pm 10 \%)$ and lighting (from 08.00 to 20.00 hours) conditions. The Cbl-deficient and control rats were allowed free access to the Cbl-deficient and -sufficient diets, respectively, and water. The Cbl-sufficient diet was identical to the deficient one with an exception that cyanocobalamin was included at $25 \mu \mathrm{g} / \mathrm{kg}$. At the ages of $10,15,20$ or 30 weeks, these rats (five rats in each group) were anaesthetised with diethyl ether, and their livers were excised.

In a Cbl-supplementation experiment, $\mathrm{Cbl}$ was fed to a group of the Cbl-deficient rats at age 20 weeks that had been moved to individual metabolism cages at age 19 weeks, for $0,1,2$ or 4 weeks, by the supplementation of cyanocobalamin into their diets at $100 \mu \mathrm{g} / \mathrm{kg}$. At the end of the feeding, the urine was sampled from these rats during the last $24 \mathrm{~h}$ of their life to measure the amount of MMA excreted into the urine, and their livers were obtained under diethyl ether anaesthesia. MMA in the urine was determined by an HPLC method as described previously ${ }^{(6)}$. To administer carnitine to the Cbl-deficient rats, $0.5 \mathrm{mmol} \mathrm{L}$-carnitine (kindly donated by Hamari Chemicals, Osaka, Japan) was dissolved in $2 \mathrm{ml}$ distilled water and adjusted to $\mathrm{pH} 7 \cdot 5$, and was intraperitoneally injected twice per $\mathrm{d}$ for 2 weeks. Furthermore, methionine was fed to the Cbl-deficient rats for 2 weeks by adding L-methionine to the diet at $4 \mathrm{~g} / \mathrm{kg}$.

All experimental procedures including the laboratory animals were approved by the Animal Care and Use Committee of Osaka Prefecture University.

\section{Enzyme assay}

The livers were homogenised in 10 volumes of $100 \mathrm{~mm}$-potassium phosphate buffer ( $\mathrm{pH} 7 \cdot 5)$, containing leupeptin $(10 \mu \mathrm{g} / \mathrm{ml})$, aprotinin $(1 \mu \mathrm{g} / \mathrm{ml})$ and $0 \cdot 1 \mathrm{mM}$-4-(2-aminoethyl)-benzenesulfonyl fluoride, by using a Teflon homogeniser at $4^{\circ} \mathrm{C}$. The homogenate was centrifuged at $15000 \mathrm{~g}$ for $10 \mathrm{~min}$, and the supernatant fraction obtained was used as a crude enzyme solution.

MCM holoenzyme and total enzyme (holoenzyme + apoenzyme) activities were determined by an HPLC method described by Gaire et al. ${ }^{(13)}$. Briefly, the crude enzyme solution in $100 \mathrm{~mm}$-potassium phosphate buffer ( $\mathrm{pH} 7 \cdot 5)$ was preincubated in the absence (in the case of the holo-MCM activity) or presence (in the case of the total-MCM activity) of $30 \mu \mathrm{M}$-AdoCbl at $37^{\circ} \mathrm{C}$ in the dark for $5 \mathrm{~min}$. The enzyme reaction was started by the addition of DL-MMA-CoA at a final concentration of $1.5 \mathrm{mmol} / \mathrm{l}$. After appropriate incubation, TCA was added at a final concentration of $3.2 \%$ (w/w) to stop the enzyme reaction. The mixture was centrifuged and the supernatant fraction obtained was filtrated. Succinyl-CoA in the filtrate, which was produced by the enzyme reaction, was analysed by an HPLC system using a reverse-phase HPLC column (COSMOSIL 5C 18 AR-II, $3.0 \times 150 \mathrm{~mm}$; Nacalai Tesque, Kyoto, Japan). The filtrate was applied onto the column equilibrated with $100 \mathrm{~mm}$-acetic acid in $100 \mathrm{mM}$-potassium phosphate buffer ( $\mathrm{pH}$ 7.5) containing 5.4\% methanol. Succinyl-CoA was eluted by a linear concentration gradient $(5.4-18 \%)$ of methanol in the elution buffer at a flow rate of $1 \mathrm{ml} / \mathrm{min}$ at $40^{\circ} \mathrm{C}$, and was monitored by measuring absorbance at $254 \mathrm{~nm}$.

\section{Preparation of anti-L-methylmalonyl-co-enyzme-A mutase antibodies}

For the preparation of the recombinant human MCM (mature form) to use as an antigen, human MCM cDNA was obtained by nested PCR. The primer sequences correspond to the human MCM sequence (accession number: NM000255). The first PCR was performed using a sense primer 1 (5'-ACAGCGGAGTCCAAAACAGGCCTA-3': positions 11-34), an antisense primer 1 (5'-CCATTGTCCAGAGTTCTTG-3': positions 2588-2570) and human brain (cerebral cortex) Marathon-ready cDNA (BD Biosciences Clontech, Palo Alto, CA, USA) as a template. The second PCR was done using a sense primer $2\left(5^{\prime}\right.$-GGGTGTTTCCATGCTCCACCATGT- $3^{\prime}$ : positions 57-80), an antisense primer 2 (5'-GCATGACACCAGGCCTATAAGTAAGG-3': positions 2486-2461) and the first PCR product as a template. The PCR product was cloned into pCR2.1 TOPO-TA vector (Invitrogen, Carlsbad, CA, USA), termed pCR2.1-hMCM. To construct the vector for the expression of the mature form of MCM in Escherichia coli, the PCR was performed using a sense primer 3 (5'-ggagatCTACACCAGCAACAGCCCCTTCA-3': positions 173-195), an antisense primer 3 (5'-gggcggccgcTTATACAGATTGCTGCTTCTTTTCC-3': positions 2329-2305) and pCR2.1-hMCM as a template. The $B g l$ II and Not I restriction sites are underlined, respectively. The PCR product was subcloned into pCR2.1 TOPO-TA vector, named pCR2.1hMCM-mature. The pCR2.1-hMCM-mature was digested with $\mathrm{Bgl}$ II and Not I, and ligated into the corresponding restriction sites of $\mathrm{pET} 30 \mathrm{a}(+)$ vector (Novagen, San Diego, CA, USA), termed pET30a(+)-hMCM-mature. The pET30a(+)-hMCM-mature was transformed into E. coli BL21 (DE3), and the transformant was cultured in the presence of $0.1 \mathrm{~mm}$-isopropyl-1- $\beta$-D-galactoside at $12^{\circ} \mathrm{C}$. The recombinant human MCM (mature form) produced was affinity purified with Ni-NTA agarose resin according to the manufacturer's instructions (Qiagen, Hilden, Germany). Anti-MCM antibodies were raised in rabbits by using the affinity-purified protein, which had been confirmed to be a single protein band on SDS-PAGE. 


\section{Western blotting}

The livers were homogenised in $20 \mathrm{~mm}-\mathrm{HEPES}-\mathrm{NaOH}$ buffer ( $\mathrm{pH} 7 \cdot 5)$, containing $1 \%$ (w/w) Nonidet P-40, aprotinin $(10 \mu \mathrm{g} / \mathrm{ml})$, leupeptin $(1 \mu \mathrm{g} / \mathrm{ml})$ and $0 \cdot 1 \mathrm{~mm}-4$-(2-aminoethyl)benzenesulfonyl fluoride, with a Teflon homogeniser at $4^{\circ} \mathrm{C}$. The homogenate was centrifuged at $15000 \mathrm{~g}$ for $10 \mathrm{~min}$, and the supernatant fraction obtained was used as the sample solution. The sample solution was subjected to SDS-PAGE, and proteins in the gel were electroblotted to a polyvinylidene difluoride membrane. The membrane was probed with rabbit anti-MCM antibodies, and immunoreactive proteins on the membrane were detected by a chemiluminescent method using a commercial kit (Super Signal West Pico Chemiluminescent substrate system; Pierce, Rockford, IL, USA) with horseradish peroxidase-conjugated goat anti-rabbit IgG antibodies. Digitised images were obtained with a luminescent image analyser (LAS-1000 Plus; Fuji Film, Tokyo, Japan), and the band intensities were quantified.

\section{Real-time polymerase chain reaction analysis}

Livers were minced in liquid $\mathrm{N}_{2}$ and mixed with Sephasol RNA1 (Nacalai Tesque) to extract total RNA, according to the manufacturer's instructions. Poly $(\mathrm{A})+$ mRNA was prepared from the total RNA sample by using Oligotex dT30 (Roche, Basel, Switzerland), and the cDNA template for real-time PCR analysis was synthesised from the poly $(\mathrm{A})+$ mRNA preparation by using oligo dT primer (dT20) and MLV RT (Promega, Madison, WI, USA). A master mix of the real-time PCR analysis consisted of the cDNA template, specific primers and SYBR Green PCR Core Reagent (Applied Biosystems, Foster City, CA, USA). PCR was carried out using OPICON2 (MJ Research, Waltham, MA, USA), according to the manufacturer's instructions. The specific primers used for the determination of the MCM mRNA level were 5'-CATGGAACGTGAAGGTCGCAGA-3' (sense primer) and 5'-AGAGGGCCTATGTCCACACATC- $3^{\prime}$ (antisense primer). For normalisation, $\beta$-actin mRNA level was also determined as the internal standard (the sense and antisense primers used were $5^{\prime}$-GGCATCCTGACCCTGAAGTA- $3^{\prime}$ and 5'-GGGGTGTTGAAGGTCTCAAA-3', respectively).

\section{Cell culture}

COS-7 (African green monkey kidney) cells were cultured in $10 \mathrm{ml}$ Dulbecco's modified Eagle's medium, containing $10 \%$ fetal bovine serum, penicillin (100 units/ml) and streptomycin $(100 \mu \mathrm{g} / \mathrm{ml})$, on a $100 \mathrm{~mm}$ dish at $37^{\circ} \mathrm{C}$ in a humidified $5 \%$ $\mathrm{CO}_{2}-95 \%$ air atmosphere. The concentration of $\mathrm{Cbl}$ in fetal bovine serum used, which was determined by the fully automated chemiluminescence B12 analyser ACS 180 (Chiron Diagnostics, East Walpole, MA, USA) according to the manufacturer's instructions, was $102 \mathrm{pmol} / \mathrm{l}$ (thus, the $\mathrm{Cbl}$ concentration in the medium is calculated to be about $10 \mathrm{pmol} / \mathrm{l})$. For the supplementation of $\mathrm{Cbl}$, hydroxocobalamin $(\mathrm{OHCbl})$ was added into the medium at a varied concentration ( $1 \mathrm{nmol} / \mathrm{l}-10 \mu \mathrm{mol} / \mathrm{l})$. After reaching confluence, the cells were harvested and homogenised in $100 \mathrm{~mm}$-potassium phosphate buffer ( $\mathrm{pH} 7 \cdot 5)$, containing leupeptin $(1 \mu \mathrm{g} / \mathrm{ml})$, aprotinin $(10 \mu \mathrm{g} / \mathrm{ml})$ and $0 \cdot 1 \mathrm{~mm}-4$-(2-aminoethyl)-benzenesulfonyl fluoride, with a Teflon homogeniser at $4^{\circ} \mathrm{C}$. The homogenate was centrifuged, and the supernatant fraction obtained was used as a crude enzyme solution for the MCM assay.

\section{Statistical analyses}

Changes in the hepatic total- and holo-MCM activities during the feeding of the experimental diets were compared between the Cbl-deficient and control groups by two-way ANOVA, and post hoc analyses were done by the Scheffé test. Other data were evaluated by one-way ANOVA, followed by the Scheffé post hoc test. These analyses were performed with GB-Stat 5.4 (Dynamic Microsystems, Silver Spring, MD, USA). All data are expressed as means and standard deviations, and statistical significance is defined as $P<0 \cdot 05$.

\section{Results}

Hepatic L-methylmalonyl-co-enzyme A mutase activity in cobalamin-deficient rats

Total-MCM activity in the liver was not significantly changed during the experimental period (age 10-30 weeks) in the control rats fed the Cbl-sufficient diet (Fig. 1). Similarly, the holo-MCM activity was also kept almost constant during the feeding of the Cbl-sufficient diet in the control rats, although it was less than $5 \%$ of the total activity. In the Cbl-deficient rats, as expected, the holo-MCM activity was hardly detected at any of the ages examined. The total-MCM activity was not significantly different between the Cbl-deficient and control groups at the age of 10 weeks. However, a marked increase in the totalMCM activity occurred in the Cbl-deficient rats, and at age 20 weeks it was about 3 -fold higher in the deficient group than in the control $(P<0 \cdot 05)$.

When the Cbl-deficient rats at age 20 weeks were fed the Cbl-supplemented diet, hepatic holo-MCM activity increased, and after 2 weeks it reached a level comparable with that in the Cbl-sufficient control group (Fig. 2). In response to the increase in the holo-MCM activity, the urinary excretion of MMA almost disappeared in the rats supplemented $\mathrm{Cbl}$ for 2 weeks. In contrast, the increased total-MCM activity in the deficient rats returned to the normal level in 1 week after the Cbl supplementation.

\section{Abnormal increase in the L-methylmalonyl-co-enzyme A mutase protein level in rat liver under the cobalamin-deficient conditions}

At age 20 weeks, the liver MCM protein level, determined by Western blotting, was significantly higher in the Cbl-deficient rats than in the controls (Fig. 3). The MCM protein level in the deficient rats returned to the normal level 2 weeks after they were put on the Cbl-supplemented diet. The MCM mRNA level, in contrast to the protein level, was decreased by $\mathrm{Cbl}$ deficiency, when determined by real-time PCR.

The Cbl-deficient rats (age 20 weeks) were administered carnitine for 2 weeks to decrease the level of toxic MMA. As reported previously ${ }^{(14)}$, the administration of carnitine to the Cbl-deficient rats reduced MMA levels in the urine from 2.99 (SD 0.370) to 0.89 (SD 0.149) $\mathrm{mmol} / \mathrm{kg}$ body weight per $\mathrm{d}$ $(P<0.05)$. However, carnitine increased (rather than decreased) 

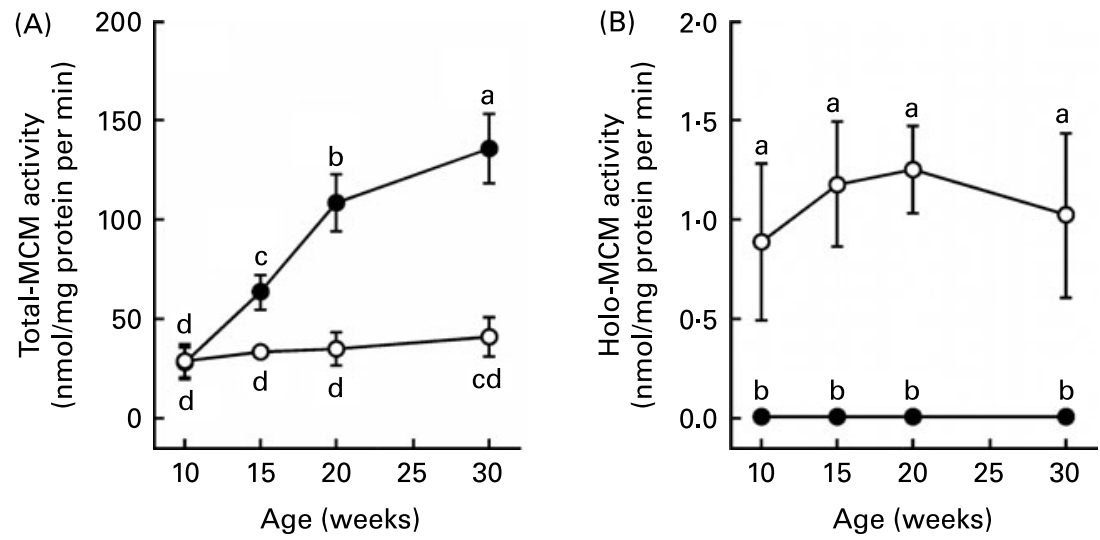

Fig. 1. Changes in hepatic total- (A) and holo- (B) methylmalonyl-CoA mutase (MCM) activities in rats maintained on a cobalamin (Cbl)-deficient diet. Weanling rats (age 3 weeks) were maintained on a diet supplemented with $\mathrm{Cbl}(25 \mu \mathrm{g}$ cyanocobalamin per $\mathrm{kg})(\mathrm{O})$ or without Cbl $(\bullet)$, and hepatic total- and holo-MCM activities were followed during the experimental period (age 10-30 weeks). Values are the means of five rats, with standard deviations represented by vertical bars. ${ }^{\text {a,b,c,d }}$ Values with unlike letters were significantly different $(P<0.05)$.

the hepatic total-MCM activity in the Cbl-deficient rats (Fig. 4). In addition, the total-MCM activity in the Cbl-deficient rats was not decreased, although methionine was supplemented into the diet to compensate for the decrease in the methionine synthesis.

Effect of cobalamin on total- and holo-L-methylmalonyl-coenyzme-A mutase activities in cultured COS-7 cells

COS-7 cells cultured without the supplementation of $\mathrm{OHCbl}$ showed hardly any holo-MCM activity (Fig. 5). Supplementation of $\mathrm{OHCbl}$ resulted in a marked increase in the holo-MCM activity in a dose-dependent manner, although the holo-MCM activity did not exceed $30 \%$ of the total-MCM activity even if $\mathrm{OHCbl}$ was supplemented at $10 \mu \mathrm{mol} / \mathrm{l}$. In contrast, the total-MCM activity was dose-dependently decreased by the supplementation of OHCbl. The activity was $2 \cdot 7$-fold higher in the cells cultured without supplementation of $\mathrm{OHCbl}$ than in the cells supplemented with $\mathrm{Cbl}$ at $10 \mu \mathrm{mol} / \mathrm{l}$.

\section{Discussion}

MCM, an AdoCbl-dependent enzyme, catalyses the isomerisation of L-MMA-CoA to succinyl-CoA. MCM participates in the last step of propionate metabolism in mammals, in which propionyl-CoA is converted to succinyl-CoA, an intermediate of the tricarboxylic acid cycle ${ }^{(1)}$. In patients with $\mathrm{Cbl}$ deficiency or with some inherited diseases that occur due to the mutation of MCM or other genes involved in the synthesis of AdoCbl, MMA accumulates in the plasma and tissues. The accumulation of MMA induces severe and recurrent metabolic acidosis that may result in vomiting, hypotonia, coma, brain damage, and death in infancy ${ }^{(7,9,10)}$

In mammals, most MCM protein occurs in the form of a non-functional apoenzyme that does not bind to AdoCbl under physiological conditions ${ }^{(13,15)}$. In the present experiment, even if rats were maintained on a diet supplemented with a sufficient level of $\mathrm{Cbl}(25 \mu \mathrm{g}$ cyanocobalamin was included per $\mathrm{kg}$ diet), the holo-MCM activity was less than $5 \%$ of the total-MCM activity in the liver at each of the ages examined (Fig. 1). Thus, it seems that synthesis of MCM protein is in excess to what is needed for normal metabolism in mammals. Furthermore, the holo-MCM activity did not exceed $30 \%$ of the total-MCM activity in COS-7 cells even if the amount of $\mathrm{OHCbl}$ supplemented into the medium was increased to $10 \mu \mathrm{mol} / \mathrm{l}$ (which is about 10000 -fold higher than the plasma concentration of $\mathrm{Cbl}$ in Cbl-sufficient rats (about $1 \mathrm{nmol} / \mathrm{l})^{(6)}$ ). These results indicate that a large part
(A)

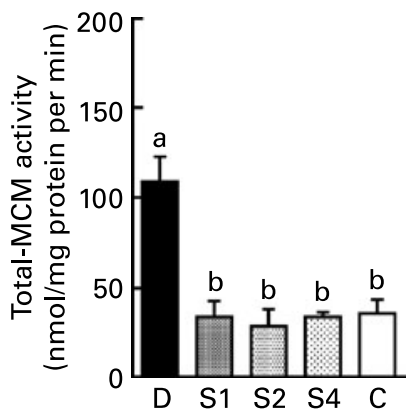

(B)

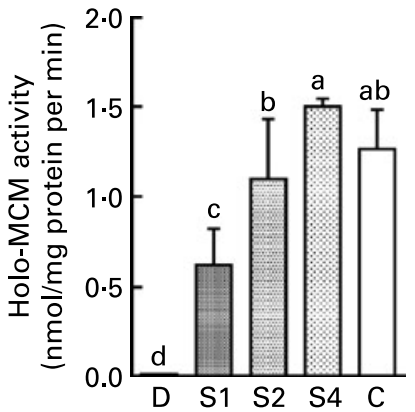

(C)

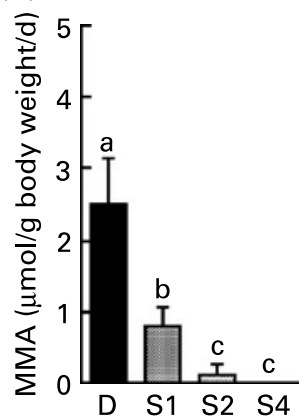

Fig. 2. Changes in hepatic total- (A) and holo- (B) methylmalonyl-CoA mutase (MCM) activities and urinary methylmalonic acid (MMA) (C) after adding cobalamin (Cbl) to the diet of Cbl-deficient rats. Cbl-deficient rats at age 20 weeks (D) were fed a Cbl-supplemented diet (100 $\mu \mathrm{g}$ cyanocobalamin per kg) for 1,2 or 4 weeks (S1, S2 and S4, respectively), and hepatic total- and holo-MCM activities and urinary MMA were determined. C, Cbl-sufficient control rats (age 20 weeks). Values are the means of five rats, with standard deviations represented by vertical bars. ${ }^{\mathrm{a}, \mathrm{b}, \mathrm{c}, \mathrm{d}}$ Values with unlike letters were significantly different $(P<0.05)$. 

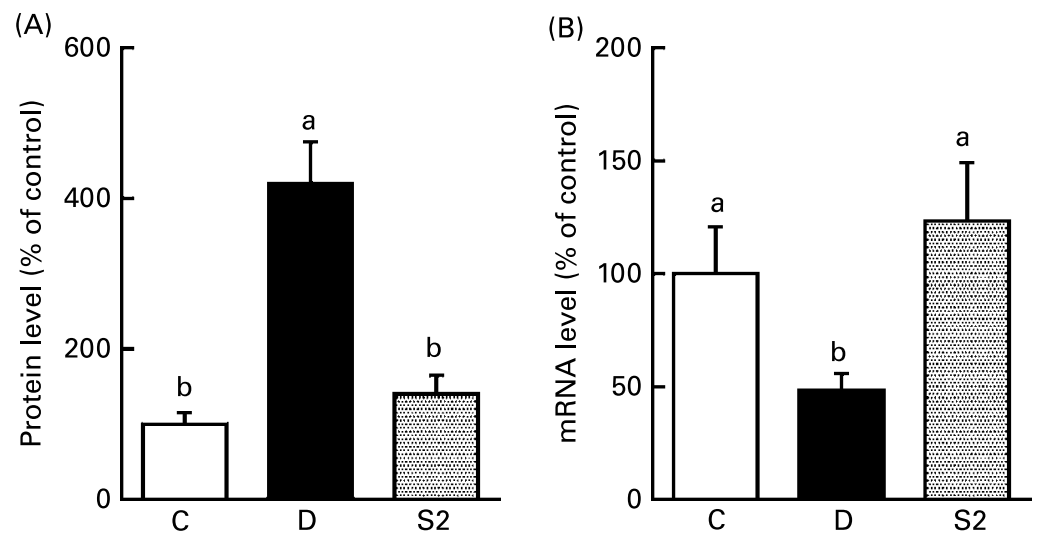

Fig. 3. Effects of cobalamin (Cbl) deficiency on methylmalonyl-CoA mutase (MCM) protein (A) and mRNA (B) levels in rat liver. MCM protein and mRNA levels were determined by Western blotting and real-time PCR, respectively. Cbl-deficient rats at age 20 weeks (D) were fed a Cbl-supplemented diet (100 $\mu \mathrm{g}$ cyanocobalamin per kg) for 2 weeks (S2). C, Cbl-sufficient control rats (age 20 weeks). Data are presented as relative values (\% of the level of the Cbl-sufficient control rats). Values are the means of five rats, with standard deviations represented by vertical bars. ${ }^{\mathrm{a}, \mathrm{b}}$ Values with unlike letters were significantly different $(P<0.05)$.

of MCM protein is kept as the catalytically inactive apoenzyme that does not bind to AdoCbl in mammalian cells even if $\mathrm{Cbl}$ is provided in excess. However, it is not clear whether the apoenzyme form of MCM has a physiologically important function in mammalian cells.

The present results show that a marked increase in the MCM protein expression occurs with a concomitant increase in the total-MCM activity in rat liver when $\mathrm{Cbl}$ deficiency becomes severe, even though virtually all of the MCM protein is in the apoenzyme form (Figs. 1 and 3). At age 20 weeks, the total-MCM activity in the liver was about 3 -fold higher in the Cbl-deficient rats than that in the Cbl-sufficient controls, and the increased activity in the deficient rats returned to the normal level in 1 week after adding $\mathrm{Cbl}$ to the diet (Fig. 2). In sheep and fruit bats, unlike in rats, $\mathrm{Cbl}$ deficiency does not induce a significant change in the total-MCM activity in the liver ${ }^{(16,17)}$. The reason for the discrepancy is unclear but

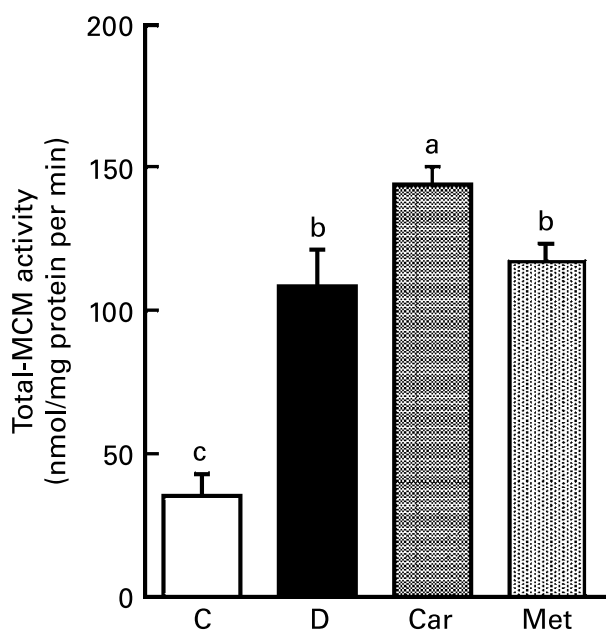

Fig. 4. Effects of carnitine (Car) and methionine (Met) on hepatic totalmethylmalonyl-CoA mutase (MCM) activity in cobalamin (Cbl)-deficient rats. Cbl-deficient rats (age 20 weeks) (D) were intraperitoneally injected with L-carnitine $(0.5 \mathrm{mmol}$ each) twice per $\mathrm{d}$ for 2 weeks (Car) or were fed a methionine-supplemented diet ( $4 \mathrm{~g}$ methionine per $\mathrm{kg}$ ) for 2 weeks (Met). $\mathrm{C}$, Cbl-sufficient control rats (age 20 weeks). Values are the means of five rats, with standard deviations represented by vertical bars. ${ }^{a, b, c}$ Values with unlike letters were significantly different $(P<0.05)$. it may be due to differences in species and/or the severity of $\mathrm{Cbl}$ deficiency. At age 20 weeks, the total-MCM activities in the cerebrum, cerebellum and kidneys were also significantly higher (1.5-fold, 1.5-fold and 3.2-fold higher, respectively) in the Cbl-deficient rats than in the controls (data not shown). The MCM mRNA level in the liver, unlike the protein level, was rather decreased by Cbl deficiency (Fig. 3). Thus, the synthesis of the MCM protein might be up-regulated translationally in rat liver under Cbl-deficient conditions. Alternatively, there is a possibility that the destruction of the MCM protein is decreased by $\mathrm{Cbl}$ deficiency. In contrast to MCM, MS, which requires methylcobalamin as a coenzyme, has been reported to decrease at the protein level (but not at mRNA level) in rat liver under Cbl-deficient conditions because of the instability of its apoenzyme ${ }^{(18)}$. In addition, MS protein expression is markedly increased in some cell types (such as HepG2 and COS-7 cells) when they are cultured in medium supplemented with $\mathrm{Cbl}$ at concentrations over $1 \mu \mathrm{mol} / \mathrm{l}^{(19)}$. It has been proposed that $\mathrm{Cbl}$ up-regulates MS at the translational level by modulating a Cbl-responsible internal ribosome entry site in the $5^{\prime}$-upstream of the MS mRNA $^{(20,21)}$

Carnitine is clinically used to treat methylmalonic aciduria in patients with $\mathrm{Cbl}$ deficiency ${ }^{(22)}$ because MMA-CoA, which is accumulated as a result of the decrease in the holo-MCM activity, is converted to non-toxic methylmalonyl-carnitine, but not toxic MMA, and excreted into the urine when carnitine is administered ${ }^{(23)}$. Indeed, we observed that liver injury induced by $\mathrm{Cbl}$ deficiency was reduced by the injection of carnitine in rats ${ }^{(14)}$. However, the hepatic total-MCM was not decreased (rather increased) by the administration of carnitine in the Cbl-deficient rats (Fig. 4). The results suggest that the accumulation of toxic MMA as a result of a decrease in the holo-MCM activity is not a primary cause of the increase in MCM protein expression in rat liver under Cbl-deficient conditions. This notion is supported by the observation that the total-MCM activity in the liver of Cbl-deficient rats returned to the normal level within 1 week after their diet was supplemented with $\mathrm{Cbl}$ even though the urinary excretion of MMA still occurred at a substantial level at this time point (Fig. 2). The holo-MS activity is lowered by $\mathrm{Cbl}$ deficiency in rat liver ${ }^{(18)}$. It has been reported that testicular injury induced 

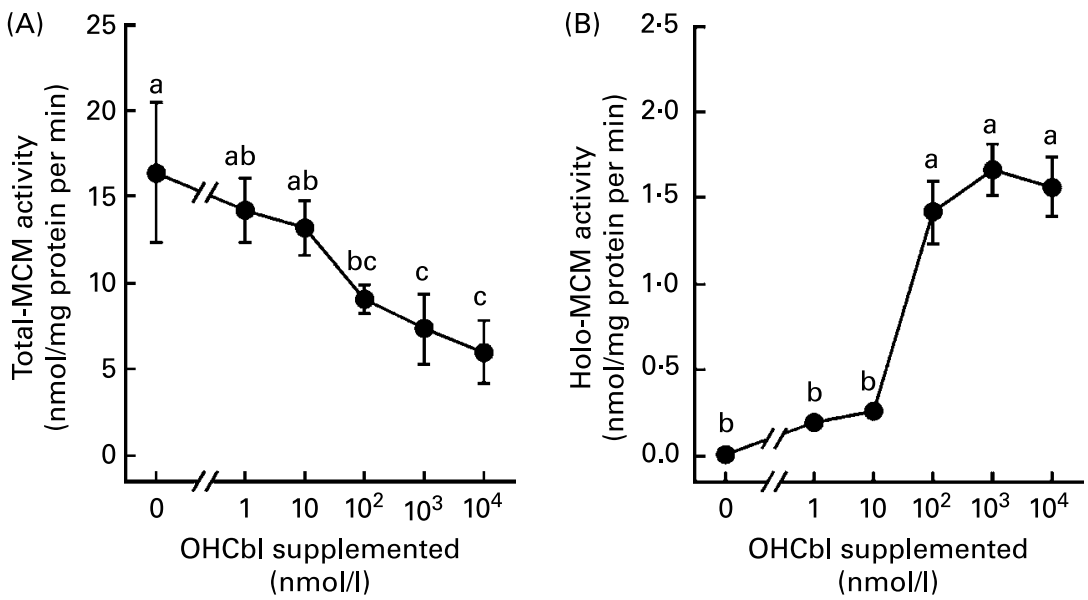

Fig. 5. Effects of cobalamin on total- (A) and holo- (B) methylmalonyl-CoA mutase (MCM) activities in COS-7 cells. The cells were cultured in $10 \mathrm{ml}$ Dulbecco's modified Eagle's medium supplemented with fetal bovine serum (10\%) and hydroxocobalamin (OHCbl) at the indicated concentrations on a $100 \mathrm{~mm}$ dish, and total- and holo-MCM activities were determined after the cells reached confluence. Values are the means of three dishes, with standard deviations represented by vertical bars. ${ }^{\mathrm{a}, \mathrm{b}, \mathrm{c}}$ Values with unlike letters were significantly different $(P<0.05)$

by $\mathrm{Cbl}$ deficiency in rats is reduced when methionine is added to the diet to compensate for a decrease in methionine synthesis ${ }^{(24)}$. However, methionine did not reduce the increased total-MCM activity in the Cbl-deficient rats (Fig. 4).

When COS-7 cells were cultured in Dulbecco's modified Eagle's medium supplemented with $10 \%$ fetal bovine serum alone (the $\mathrm{Cbl}$ concentration in the medium was estimated to be about $10 \mathrm{pmol} / \mathrm{l}$, which is considerably lower even compared with the plasma concentration of $\mathrm{Cbl}$ in deficient rats $\left.(150 \mathrm{pmol} / \mathrm{l})^{(6)}\right)$, the holo-MCM activity was below the detection limit $(5 \mathrm{pmol} / \mathrm{mg}$ protein per $\mathrm{min}$ ) (Fig. 5). Thus, it appears that the holo-MCM activity is not necessary in COS-7 cells to maintain normal cell physiology. Indeed, MMA was barely excreted into the medium even if COS-7 cells were cultured under the Cbl-deficient conditions (the concentration of MMA in the spent culture medium, which was measured by HPLC with intramolecular excimer-forming fluorescence derivatisation ${ }^{(7)}$, was 1.18 (SD 0.232) $\mu \mathrm{mol} / 1$ ( $n$ 3), which is very much lower than the plasma concentration of MMA reported in Cbl-deficient rats $\left.(750 \mu \mathrm{mol} / \mathrm{l})^{(5)}\right)$. Adding $\mathrm{Cbl}$ to the medium at concentrations higher than $100 \mathrm{nmol} / \mathrm{l}$ increased the holo-MCM activity by more than 100-fold, reaching a level comparable with or higher than that in rat liver under Cbl-sufficient conditions (about $1 \mathrm{nmol} / \mathrm{mg}$ protein per $\mathrm{min}$ ). For comparison, the holo-MS activity of COS-7 cells cultured in a medium in which fetal bovine serum was the sole $\mathrm{Cbl}$ source was about $50 \mathrm{pmol} / \mathrm{mg}$ protein per min, and increased about 4fold when $\mathrm{Cbl}$ was added at a concentration of $3.7 \mu \mathrm{mol} /$ $1^{(19)}$. In contrast to the holo-MCM activity, the total-MCM activity was dose-dependently decreased by the supplementation of $\mathrm{Cbl}$ in COS-7 cells (Fig. 5), indicating that $\mathrm{Cbl}$ deficiency results in an increase in MCM protein level in COS-7 cells as well as rat liver.

\section{Acknowledgements}

We are grateful to Hamari Chemicals (Osaka, Japan) for the donation of L-carnitine. The present study was supported in part by a Sasakawa Scientific Research Grant from The Japan Science Society (no. 18-178 to M. N.) and by Grantsin-Aid for Scientific Research from the Japan Society for the Promotion of Science (16380092 to Y. N. and 17580116 to H. I.). There is no conflict of interest that we should disclose. M. N. contributed to the data analysis and manuscript preparation. S. H. analysed the data. N. H., T. A., T. B. and Y. Y. conducted the data analysis. F. W., T. M. and Y. N. were involved in the discussion and design of the study. H. I. and R. Y., who drafted the manuscript, also contributed to the study design.

\section{References}

1. Stabler SP (1999) $B_{12}$ and nutrition. In Chemistry and Biochemistry of $B_{12}$, pp. 343-365 [R Banerjee, editor]. New York: Wiley.

2. Ludwig ML \& Matthews RG (1997) Structure-based perspectives on $\mathrm{B}_{12}$-dependent enzymes. Аnпи Rev Biochem 66, 269-313.

3. Shane B (1985) Vitamin $\mathrm{B}_{12}$-folate interrelationships. Ann Rev Nutr 5, 115-141.

4. Brass EP, Tahiliani AG, Allen RH \& Stabler SP (1990) Coenzyme A metabolism in vitamin B-12-deficient rats. $J$ Nutr 120, 290-297.

5. Toyoshima S, Watanabe F, Saido H, Pezacka EH, Jacobsen DW, Miyatake K \& Nakano Y (1996) Accumulation of methylmalonic acid caused by vitamin $\mathrm{B}_{12}$-deficiency disrupts normal cellular metabolism in rat liver. Br J Nutr 75, 929-938.

6. Ebara S, Toyoshima S, Matsumura T, Adachi S, Takenaka S, Yamaji R, Watanabe F, Miyatake K, Inui H \& Nakano Y (2001) Cobalamin deficiency results in severe metabolic disorder of serine and threonine in rats. Biochim Biophys Acta 1568, $111-117$

7. Al-Dirbashi OY, Jacob M, Al-Hassnan Z, Chabayta RW, El-Badaoui F \& Rashed MS (2005) Determination of methylmalonic acid in urine by HPLC with intramolecular excimer-forming fluorescence derivatization. Biomed Chromatogr 20, 54-60.

8. Toyoshima S, Watanabe F, Saido H, Miyatake K \& Nakano Y (1995) Methylmalonic acid inhibits respiration in rat liver mitochondria. J Nutr 125, 2846-2850. 
9. Rosenblatt DS \& Cooper BA (1987) Inherited disorders of vitamin $\mathrm{B}_{12}$ metabolism. Blood Rev 1, 177-182.

10. Thiele J \& Van Raamskonk JM (2006) Gene discovery in methylmalonic aciduria and homocystinuria. Clin Genet 69, 402-403.

11. Peters H, Nefedov M, Sarsero J, Pitt J, Fowler KJ, Gazeas S, Kahler SG \& Ioannou PA (2003) A knock-out mouse model for methylmalonic aciduria resulting in neonatal lethality. J Biol Chem 278, 52909-52913.

12. Ebara S, Nakao M, Tomoda M, Yamaji R, Watanabe F, Inui H \& Nakano Y (2008) Vitamin $B_{12}$ deficiency results in the abnormal regulation of serine dehydratase and tyrosine aminotransferase activities correlated with impairment of the adenylyl cyclase system in rat liver. Br J Nutr 99, 503-510.

13. Gaire D, Sponne I, Droesch S, Charlier A, Nicolas JP \& Lambert D (1999) Comparison of two methods for the measurement of rat liver methylmalonyl-CoA mutase activity: HPLC and radioisotopic assays. $J$ Nutr Biochem 10, 56-62.

14. Nakao M, Kono N, Adachi S, Ebara S, Adachi T, Miura T, Yamaji R, Inui H \& Nakano Y (2006) Abnormal increase in the expression level of proliferating cell nuclear antigen (PCNA) in the liver and hepatic injury in rats with dietary cobalamin deficiency. J Nutr Sci Vitaminol 52, 168-173.

15. Riedel B, Ueland PM \& Svardal AM (1995) Fully automated assay for cobalamin-dependent methylmalonyl CoA mutase Clin Chem 41, 1164-1170.

16. Kennedy DG, Cannavan A, Molloy A, O'Harte F, Taylor SM, Kennedy S \& Blanchflower WJ (1990) Methylmalonyl-CoA mutase (EC 5.4.99.2) and methionine synthase (EC 2.1.1.13) in the tissues of cobalt-vitamin $\mathrm{B}_{12}$ deficient sheep. Br J Nutr 64, 721-732.
17. Vieira-Makings E, Chetty N, Reavis SC \& Metz J (1991) Methylmalonic acid metabolism and nervous-system fatty acids in cobalamin-deficient fruit bats receiving supplements of methionine, valine and isoleucine. Biochem J 275, 585-590.

18. Yamada K, Kawata T, Wada M, Isshiki T, Onoda J, Kawanishi T, Kunou A, Tadokoro T, Tobimatsu T, Maekawa A \& Toraya T (2000) Extremely low activity of methionine synthase in vitamin B-12-deficient rats may be related to effects on coenzyme stabilization rather than to changes in coenzyme induction. $J$ Nutr 130, 1894-1900.

19. Gulati S, Brody LC \& Banerjee R (1999) Posttranscriptional regulation of mammalian methionine synthase by $\mathrm{B}_{12}$. Biochem Biophys Res Commun 259, 436-442.

20. Oltean S \& Banerjee R (2003) Nutritional modulation of gene expression and homocysteine utilization by vitamin $\mathrm{B}_{12}$. J Biol Chem 278, 20778-20784.

21. Oltean S \& Banerjee R (2005) A B B -responsive internal ribosome entry site (IRES) element in human methionine synthase. J Biol Chem 280, 32662-32668.

22. Takeuchi M, Harada M, Matsuzaki K, Hisaoka S, Nishitani H \& Mori K (2003) Magnetic resonance imaging and spectroscopy in a patient with treated methylmalonic acidemia. J Comput Assist Tomogr 27, 547-551.

23. Brass EP \& Ruff LJ (1989) Effect of carnitine on propionate metabolism in the vitamin B-12-deficient rats. J Nutr 119, 1196-1202.

24. Yamada K, Kawata T, Wada M, Mori K, Tamai H, Tanaka N, Tadokoro T, Tobimatsu T, Toraya T \& Maekawa A (2007) Testicular injury to rats fed on soybean protein-based vitamin $\mathrm{B}_{12}$-deficient diet can be reduced by methionine supplementation. J Nutr Sci Vitaminol (Tokyo) 53, 95-101. 